www.jmscr.igmpublication.org

Impact Factor 5.84

Index Copernicus Value: 71.58

ISSN (e)-2347-176x ISSN (p) 2455-0450

crossref DOI: _https://dx.doi.org/10.18535/jmscr/v5i11.143

Journal Of Medical Science And Clinical Research

\title{
Study on Demographic \& Clinical Profile of Children with Bronchiolitis AGED 2 - 24 Months
}

\author{
Authors \\ Vahini $\mathrm{V}^{\mathbf{1}}$, Balachandran $\mathrm{CS}^{2}$, Chidambaranathan $\mathrm{S}^{3}$ \\ ${ }^{* 1}$ Post graduate, Department of Pediatrics, Rajah Muthiah Medical College \& Hospital, Annamalai \\ University, Annamalai Nagar, Chidambaram - 608002, Tamilnadu, India \\ ${ }^{2}$ Professor,Department of Pediatrics, Rajah Muthiah Medical College \&Hospital, Annamalai University, \\ Annamalai Nagar, Chidambaram - 608002, Tamilnadu, India \\ ${ }^{3}$ Associate Professor, Department of Pediatrics, Rajah Muthiah Medical College \& Hospital, Annamalai \\ University, Annamalai Nagar, Chidambaram - 608002, Tamilnadu, India
}

\begin{abstract}
Background: Bronchiolitis is one of the most common lower respiratory tract infection in the children aged two months to twenty four months. The illness is often caused by viral infection with varying clinical presentation.

Objectives: The objective of this study is to analyse the demographic characteristics, clinical features and risk factors in children with bronchiolitis.

Materials and Methods: This was a descriptive study conducted in children attending Paediatrics department at a tertiary care centre in Chidambaram, Tamilnadu with clinical diagnosis of bronchiolitis aged 2 to 24 months. Children were enrolled as per inclusion criteria.The demographic characteristics, clinical features and major risk factors of admitted children were studied.

Results: Seventy five children with clinical diagnosis of bronchiolitis were enrolled for study. Forty six (61\%) children were male. Mean age was $6.32 \pm 4.09$ months. Male to female ratio was 1.5:1.Risk factors predisposing to bronchiolitis were analysed in the admitted children. Twenty-one (28\%) children were premature at birth. Nineteen (25\%) children had Low birth weight ( $<2500$ grams). Overcrowding in house was present in seventeen (22\%) children and eighteen (24\%) had exposure to passive smoking. Eight (10\%) children were malnourished. The most common clinical symptoms observed were cough, dyspnoea and fever. Major clinical signs at the time of admission were chest retractions, wheezing and tachypnea.

Conclusion: Bronchiolitis was primarily seen in children of age 2-6 months, with male predominance. Major risk factors observed were prematurity, low birth weight and passive smoking. Cough, dyspnoea and fever were most common symptoms. Chest retractions and wheeze were major signs.

Keywords: Bronchiolitis, Clinical profile, Risk factors, Wheeze.
\end{abstract}

\section{Introduction}

Bronchiolitis is a clinical diagnosis described as "a constellation of clinical symptoms and signs including a viral upper respiratory prodrome of rhinorrhea, cough, fever which is followed by increased respiratory effort manifested as grunting, nasal flaring, intercostal and subcostal retractions, wheezing and diffuse bilateral crackles in children less than 12 months of age" by the European Respiratory Society (ERS) and in 
children no less than 24 months by the American Academy of Paediatrics (AAP). ${ }^{[1,2]}$

The epidemiologic factors associated with Bronchiolitis were prematurity, passive smoking, young age, low birth weight,male sex,lack of breastfeeding, chronic lung disease, congenital heart disease, viral coinfection, maternal smoking during pregnancy, mechanical ventilation in the neonatal period, maternal history of atopy and/or asthma during pregnancy, season of birth, low socioeconomic status, Down syndrome and environmental pollution. ${ }^{[3]}$

Main pathology in bronchiolitis was bronchial obstruction due to increased mucus secretion, alveolar cell death and debris. This will result in air trapping, atelectasis, ventilation-perfusion mismatch and hypoxia (4). Diagnosis of bronchiolitis was clinical and characterized by fever, tachypnea, and wheezing. Other symptoms and signs are cough, cyanosis, and irritability ${ }^{(5)}$

The study was conducted to determine demographic features, clinical manifestations, and risk factors in our children who were admitted due to bronchiolitis.

\section{Materials and Methods}

The study was conducted in Department of Pediatrics, Rajah Muthiah Medical College and Hospital, Chidambaram for the study period of 18 months.

\section{Inclusion criteria}

Children with history of a preceding viral upper respiratory infection followed by chest retractions and wheeze in the age group of 2 to 24 months were included for the study.

\section{Exclusion criteria}

Children who had history of recurrent or previous episode of wheeze, Congenital heart disease, Immunodeficiency, Grade III or grade IV Protein energy malnutrition, Whose parents denied consent, Who present with Pulse >200/min, Respiratory rate $>80 / \mathrm{min}$, Oxygen saturation < 94\% despite oxygen therapy, profound lethargy, altered sensorium, and convulsions were excluded from study.
Detailed history was taken and details were filled in the case proforma.

Clinical features at the time of admission were examined and recorded.

\section{Results}

In present study, seventy five children with bronchiolitis were evaluated for clinical features and risk factors. Children in the age group 2-6 months were more commonly affected. Forty six $(61 \%)$ children were less than 6 months of age. Mean age in our study was $6.32 \pm 4.09$ months. Forty five $(60 \%)$ of admitted children were male with a male to female ratio of 1.5:1.

Clinical features of admitted children were studied. Most common symptom was cough (100\%), followed by dyspnoea (96\%) and fever $(80 \%)$

Most common signs observed were wheeze $(100 \%)$ and chest retractions $(98.7 \%)$ followed by tachypnea (96\%). Clinical features were tabulated in Table 1

Table - 1: Clinical Profile

\begin{tabular}{|l|c|c|}
\hline Clinical features & \multirow{2}{*}{ Number } & \multirow{2}{*}{ Percentage } \\
\cline { 1 - 2 } Symptoms & 75 & 100 \\
\hline Cough & 74 & 98.7 \\
\hline Cold & 60 & 80 \\
\hline Fever & 72 & 96 \\
\hline Dyspnea & 51 & 68 \\
\hline Lethargy & 38 & 50.7 \\
\hline Noisy breathing & \multicolumn{2}{|c|}{} \\
\hline Signs & 75 & 100 \\
\hline Consciousness & 58 & 77.3 \\
\hline Febrile & 04 & 5.3 \\
\hline Cyanosis & 72 & 96 \\
\hline Tachypnea & 16 & 21.3 \\
\hline Grunting & 55 & 73.3 \\
\hline $\begin{array}{l}\text { Accessory } \\
\text { usage }\end{array}$ & 74 & 98.7 \\
\hline Chest Retractions & 75 & 100 \\
\hline Wheeze & &
\end{tabular}

Risk factors predisposing to bronchiolitis in admitted children were evaluated in which we observed, twenty-one (28\%) children were born prematurely below 37 weeks and nineteen $(25 \%)$ children had birth weight less than 2500 grams. seventeen $(22 \%)$ children had overcrowding in 
their house and eighteen (24\%) had exposure to passive smoking. Eight $(10 \%)$ children were malnourished. Risk factors in admitted children were presented in Table 2.

Table - 2: Associated Risk factors in children with Bronchiolitis

\begin{tabular}{|l|c|c|}
\hline Risk factors & $\begin{array}{c}\text { Number of } \\
\text { children }\end{array}$ & Percentage \\
\hline Pre Term & 21 & 28 \\
\hline Low Birthweight & 19 & 26 \\
\hline Over Crowding & 17 & 22.7 \\
\hline Passive smoking & 18 & 24 \\
\hline Nutrition & 8 & 10.7 \\
\hline
\end{tabular}

\section{Discussion}

Bronchiolitis, one of the common lower respiratoryinfections is an important cause of morbidity and also acommon cause of hospitalization in infants and children ${ }^{(6)}$.

In the present study, seventy five children with clinical diagnosis of bronchiolitis were evaluated. Children of age 2-6 months constituted the major group in our study. Forty six children (61\%) had age less than 6 months. Nasrin Hoseiny Nejad $(77 \%)^{(7)}$ and Boniface Flevey Makam et al $(54.8 \%)^{(8)}$ studies showed similar results where they conclude that Bronchiolitis typically affects children younger than two years with a peak incidence between two and six months of age:

Male children were most commonly affected in current study accounting for $60 \%$ of all admissions, similar to Ganavi et $\mathrm{al}^{(1)}$ study where they had $63.6 \%$ of male babies. The male: female ratio in our study was $1.5: 1$, which was similar with Constanze Sommer et al, ${ }^{(9)}$ Iqbal et al ${ }^{(10)}$ and Makem $^{(7)}$ et al studies where they got the male: female ratio of 1.42:1, 1.3:1 and 1.26:1 respectively.

Clinical manifestations at the time of admission were observed in the current study. All the seventy five children had cough (100\%), and dyspnoea (96\%), fever for $80 \%$ of children similar to studies done by Gokce et al, ${ }^{(11)}$ in which all the children in their study had cough $(100 \%)$ and fever for $88 \%$ children. In Ganavi et al ${ }^{(1)}$ study all the children had cough and in Soleimani et $\mathrm{al}^{(12)}$ study, $89 \%$ babies had cough, with fever for $72 \%$ and dyspnoea for $71 \%$ of children.

In Gokce et $\mathrm{al}^{(11)}$ and Soleimani et al ${ }^{(12)}$ study wheezing was present in $58 \%$ and $79 \%$ of children in contrast to our study where all the children presented with wheeze $(100 \%)$. In Iqbal et $\mathrm{al}^{(10)}$, study, $91 \%$ children had respiratory distress at the time of presentation. Tachypnoea was present in $96 \%$ and chest retractions in $98.7 \%$ of children in our study similar to Ganavi et al study ${ }^{(1)}$ where they found tachypnea and chest indrawing in $100 \%$ of children. Severe signs like cyanosis and apnea are less common in our study, only 4 have cyanosis and none of the children had apnea. But in Gholamreza Soleimani ${ }^{(12)}$ et al study, they observed apnea in $14 \%$ of children.

\section{Recommendations}

Risk factors like premature delivery and low birth weight can be decreased by good antenatal care and regular follow up. Awareness about household smoking and its harmful effect on infants should be educated to parents. Improving nutrition and encouraging exclusive breast feeding in children decreases the incidence of respiratory infection.

\section{Conclusion}

Bronchiolitis was primarily seen in children less than one year with majority of them in 2-6 months of age group with male predominance. Major risk factors observed were prematurity, low birth weight and passive smoking. Cough, dyspnoea and fever were most common symptoms observed. Most common signs noticed in the present study were wheeze, chest retractions and tachypnea.

\section{References}

1. Ganavi Ramagopal, Edin Brow, Alexander Mannu, Jaishree Vasudevan, Lalaumadevi Demographic, clinical and hematological profile of children with bronchiolitis: A Comparative Study between Respiratory Synctial Virus [RSV] and [Non RSV] 
Groups. Journal of clinical and diagnostic research, 2016 Aug. Vol-10[8]

2. Claudia Ravaglia and Venerino Poletti* Recent advances in the management of acute bronchiolitis F1000Prime Reports 2014, 6:103 (doi:10.12703/P6-103)

3. Alvarez AE, Marson FA, Bertuzzo CS, Arns CW, Ribeiro JD. Epidemiological and genetic characteristics associated with the severity of acute viral bronchiolitis by respiratory syncytial virus. J Pediatr (Rio J).2013;89: 531-43.

4. Johnson JE, GonzalesRA, Olson SJ, Wright PF, Graham BS. The histopathology of fatal untreated humanrespiratory syncytial virus infection. Mod Pathol.2007; 20(1): 108-19

5. Wainwright $\mathrm{C}$ : Acute viral bronchiolitis in children- a very common condition with few therapeutic options. Paediatr Respir Rev; 2010, 11:39-45

6. Nishant verma, Rakesh lodha, SK Kabra Recent advances in management of bronchiolitis: Volume 50-October 15, 2013

7. Nasrin Hoseiny Nejad, Bronchiolitis in young children: Demographic features, risk factors and seasonal patterns IJCA, Vol. 3, No. 1, Feb, 2017.5-7.

8. Fievey Makam, B., Wakamb Kanteng, G.A., Wembonyama, S.O. and Numbi Luboya, O. (2017) Epidemiological, Nutritional and Factors Associated with Infant Bronchiolitis in Hospitals: Case of the City of Lubumbashi (DRCongo). Open Access Library Journal , 4:e3710.

9. Constanze Sommer, Bernhard Resch, ${ }^{*}$ and Eric A.F. Simões :Risk Factors for Severe Respiratory Syncytial Virus Lower RespiratoryTract InfectionThe Open Microbiology Journal, 2011, 5, (Suppl 2M4) 144-154

10. Iqbal SMJ, Afzal MF, Sultan MA. Acute bronchiolitis: epidemiological and clinical [15] study. Annals. 2009;15(4):203-05.
11. ŞuleGökçe, ZaferKurugöl,

Güldane Koturoğlu, Candan Çiçek, and AslıAslan, Etiology, Seasonality, and Clinical Features of Viral Respiratory Tract Infections in Children Hospitalized With Acute Bronchiolitis: April 3, 2017.

12. Gholamreza Soleimani1; Elham Shafighi Shahri2; Somayeh Rashidi2; Zahra Salari2; Alireza Ansari Moghadam Epidemiology, Clinical, and Laboratory Characteristics of Bronchiolitis in Hospitalized Children J ComprPed. 2014 August; 5(3): e18808. 